\title{
How Do Gender Differences in Quality of Care Vary Across Medicare Advantage Plans?
}

\author{
Chloe E. Bird, PhD ${ }^{7}$, Marc N. Elliott, PhD' , John L. Adams, PhD², Eric C. Schneider, MD ${ }^{3}$, \\ David J. Klein, $M S^{7}$, Jacob W. Dembosky, MPM${ }^{4}$, Sarah Gaillot, PhD ${ }^{5}$, Allen M. Fremont, PhD, MD', \\ and Amelia M. Haviland, $P h D^{4,6}$ \\ 'RAND Corporation, Santa Monica, CA, USA; ${ }^{2}$ Kaiser Permanente Center for Effectiveness \& Safety Research, Pasadena, CA, USA; ${ }^{3}$ The \\ Commonwealth Fund, New York, NY, USA; ${ }^{4}$ RAND Corporation, Pittsburgh, PA, USA; ${ }^{5}$ Centers for Medicare \& Medicaid Services, Baltimore, MD, \\ USA; ${ }^{6}$ Carnegie Mellon University, Pittsburgh, PA, USA.
}

\begin{abstract}
BACKGROUND: Healthcare Effectiveness Data and Information Set (HEDIS) quality measures have long been used to compare care across health plans and to study racial/ ethnic and socioeconomic disparities among Medicare Advantage (MA) beneficiaries. However, possible gender differences in seniors' quality of care have received less attention.
\end{abstract}

OBJECTIVE: To test for the presence and nature of any gender differences in quality of care across MA Plans, overall and by domain; to identify those most at risk of poor care.

DESIGN: Cross-sectional analysis of individual-level HEDIS measure scores from 23.8 million records using binomial mixed-effect models to estimate the effect of gender on performance. For each measure, we assess variation in gender gaps and their correlation with plan performance.

PARTICIPANTS: Beneficiaries from 456 MA plans in 2011-2012 HEDIS data.

MAIN MEASURES: Performance on 32 of 34 HEDIS measures which were available in both measurement years. The two excluded measures had mean performance scores below 10\%.

KEY RESULTS: Women experienced better quality of care than men for 22/32 measures, with most pertaining to screening or treatment. Men experienced better quality on nine measures, including four related to cardiovascular disease and three to potentially harmful drug-disease interactions. Plans varied substantially in the magnitude of gender gaps for 21/32 measures; in general, the gender gap in quality of care was least favorable to men in lowperforming plans.

CONCLUSIONS: Women generally experienced better quality of care than men. However, women experienced poorer care for cardiovascular disease-related intermediate outcomes and potentially harmful drug-disease interactions. Quality improvement may be especially important for men in low-performing plans and for cardiovascular-related care and drug-disease interactions for women. Gender-stratified reporting could reveal gender gaps, identify plans for which care varies by gender, and motivate efforts to address faults and close the gaps in the delivery system.

Received December 12, 2017

Revised May 29, 2018

Accepted July 13, 2018

Published online August 10, 2018
KEY WORDS: health care delivery; health services research; Medicare; performance measurement; women's health.

J Gen Intern Med 33(10): 1752-9

DOI: $10.1007 / \mathrm{s} 11606-018-4605-5$

(C) Society of General Internal Medicine 2018

\section{INTRODUCTION}

Increased attention has been paid to clinical quality of care and whether it differs by socioeconomic status or race/ethnicity. ${ }^{1-6}$ However, there has been less recent focus on gender health equity. A small body of research suggests unexplained differences in the quality of health care received by women and men. ${ }^{7,8}$ In general, care-seeking and adherence are higher among women than among men, with women scoring higher on preventive care measures, including many screening measures. Less clear is whether this advantage extends to other aspects of care or intermediate outcomes. Some have found lower quality of cardiovascular disease and HIV/AIDS for women $^{9-13}$ and have argued that these exceptions suggest a lingering bias in how women are treated for these diseases. ${ }^{14,15}$

Gender gaps in care for seniors could have substantial health and cost consequences due to high prevalence of comorbidities (which may confound prevention and treatment), higher socioeconomic vulnerability than the general population, and higher mortality risk.

Prior work finds that racial/ethnic gaps in quality of care vary across MA plans. ${ }^{5,6,16}$ This study examines the extent to which gender differences in quality of care vary across Medicare Advantage (MA) plans and whether quality of care is higher among women or men on cardiovascular disease measures. ${ }^{1-4,7,9,11,12}$ Here, we examine the direction, size, and nature of gender gaps in MA plans. We focus on three questions.

First, how did performance scores differ by gender among MA beneficiaries? Consistent gaps across measures would indicate a need to improve overall care for one gender. Alternatively, gaps that differ by measure would suggest focus on the care of one gender in those areas. These patterns would warrant different quality improvement strategies to close 
observed gaps. For example, if women are generally more internally motivated to seek care, men might especially benefit from nudges that help those who are less activated.

Second, did the MA plans that provided the highest quality care for women also tend to do so for men? Here, we ask whether there is a plan-level gender gap that varies among plans. If the gap varies little, both women and men can use plan performance scores as an accurate quality indicator for their gender. If gender gaps vary substantially, gender-specific performance reporting might better inform MA beneficiaries about the plans that would offer them the best care. Such reporting might also illustrate differential improvement in men's or women's care in response to interventions.

Third, if gender gaps in care differ by plan, are gaps more favorable to one gender where quality of care is high? Determining whether and how care falls short for one or both genders could inform interventions to improve overall quality and to address gender gaps.

\section{METHODS}

\section{Data}

We used 2011 and 2012 Healthcare Effectiveness Data and Information Set (HEDIS) data. HEDIS data is collected by the Centers for Medicare and Medicaid Services (CMS) and consists of health care process measures and intermediate outcome measures based on individual-level administrative data, supplemented in some cases by information from medical records. ${ }^{17}$ These measures represent the state of the art in measuring health plan performance; they are used to evaluate services for which evidence indicates that measure improvement improves health outcomes. ${ }^{18,19}$ Each measure specifies inclusion criteria based on age, disease presence, and also specifies relevant exclusions (such as contraindications) that define the sample for each HEDIS measure. ${ }^{20}$

An MA contract, hereafter called a plan, is a set of offerings (or benefit packages) from a single sponsor, usually in a specific geographic area.

\section{Sample}

The analytic sample includes 23.8 million HEDIS records (unique combinations of measure, person, and year) for MA beneficiaries enrolled in any of 456 reporting plans operating in $2011{ }^{1}$

\section{Variables}

Our dependent variables were 34 HEDIS measures available in both measurement years after excluding 2 measures with limited variation (having a pass rate above $95 \%$ or below $5 \%$ ). We examined (see Table 1) 9 screening measures (3 primary

${ }^{1}$ MA plans with fewer than 1000 enrollees were exempt from the reporting requirements, as were a few types of plans. screening measures and 6 secondary screening measures for beneficiaries with specific conditions), 17 treatment measures, 5 intermediate outcome measures, and 1 access measure. There are 6 "count" measures, for which an individual beneficiary may have more than one eligible event (the anticonvulsant and summary medicine monitoring measures, the 2 measures for pharmacotherapy management of Chronic Obstructive Pulmonary Disease exacerbation, and the 2 measures for follow-up after hospitalization for mental illness). All other HEDIS measures are coded $1=$ yes and $0=$ no. We reversecoded 3 measures of drug-disease interaction prevalence so that a higher score corresponds to better care for all measures. Thus, a higher value reflects better quality of care for all measures examined.

\section{Analytic Approach}

For each HEDIS measure, we calculate national performance scores by gender.

To address our first research question, we estimate femalemale differences both within plan and overall. We fit two-level binomial mixed-effect models ${ }^{21}$ using individual-level HEDIS scores as outcomes, fixed effects for gender, random plan intercepts, and random plan slopes for female-male; these models account for clustering of patients within contracts. This approach reduces the likelihood that any apparent convergence of quality of care by gender at high or low levels of quality of care reflects a mere ceiling or floor effect. Because the official scoring specifications for HEDIS measures do not involve case-mix adjustment, no other covariates were included.

We employ the same models to address the second and third research questions by calculating the informativeness of gender-specific plan scores. Conceptually, a measure is informative if the gender gap (here the female minus male difference within a plan) varies from plan to plan, and the best plan for men is not necessarily the best plan for women. More formally, informativeness is the proportion of variance in plan scores for one gender that cannot be predicted from the overall plan scores. ${ }^{16}$ It is 0 if gender gaps are constant across plans and 1 if men's and women's scores are uncorrelated at the plan level. See Table 2 notes regarding the calculation of informativeness.

To illustrate the correlations between plan performance and plan gender gap graphically for each HEDIS measure, we classified plan into quintiles based on their performance score on that measure. Within each quintile, we calculated and plotted women's and men's performance scores.

\section{RESULTS}

Table 1 shows the percentage of MA beneficiaries receiving the indicated care - the performance score - by gender for each measure. All gender differences were statistically significant $(p<0.05)$, except for antidepressant medication 
Table 1 National HEDIS Performance Scores by Gender

\begin{tabular}{|c|c|c|c|}
\hline \multirow[b]{2}{*}{ Outcome ( $\mathrm{N}$ for women; men) } & \multicolumn{3}{|c|}{ Performance score } \\
\hline & Women & Men & W-M difference \\
\hline \multicolumn{4}{|l|}{ Primary screening } \\
\hline Adult BMI assessment $(676,978 \mathrm{~W} ; 546,623 \mathrm{M})$ & $51.0 \%$ & $49.8 \%$ & $1.2 \%+$ \\
\hline Colorectal cancer screening $(1,257,314 \mathrm{~W} ; 1,044,751 \mathrm{M})$ & $56.8 \%$ & $55.3 \%$ & $1.6 \%$ \\
\hline Glaucoma screening in older adults $(6,930,533 \mathrm{~W} ; 4,959,258 \mathrm{M})$ & $70.2 \%$ & $64.7 \%$ & $5.5 \%+8$ \\
\hline \multicolumn{4}{|l|}{ Secondary screening } \\
\hline Cardio LDL-C screening ${ }^{2}(159,098 \mathrm{~W} ; 277,173 \mathrm{M})$ & $88.3 \%$ & $88.8 \%$ & $-0.5 \%$ \\
\hline Diabetes LDL-C screening $(436,119 \mathrm{~W} ; 424,980 \mathrm{M})$ & $86.4 \%$ & $85.2 \%$ & $1.2 \%$ \\
\hline Diabetes HbA1c testing $(401,110 \mathrm{~W} ; 384,605 \mathrm{M})$ & $89.6 \%$ & $87.5 \%$ & $2.1 \% \ddagger$ \\
\hline Diabetes eye exam $(383,125 \mathrm{~W} ; 369,053 \mathrm{M})$ & $58.9 \%$ & $52.7 \%$ & $6.3 \%+\S$ \\
\hline Diabetes medical attention for nephropathy (microalbumin test or ACEI/ARB use) $(308,829 \mathrm{~W}$; & $86.3 \%$ & $85.5 \%$ & $0.8 \% \leftarrow^{3}$ \\
\hline $294,879 \mathrm{M})$ & & & \\
\hline Spirometry in dx of $\operatorname{COPD}^{2}(231,083 \mathrm{~W} ; 192,568 \mathrm{M})$ & $32.1 \%$ & $32.5 \%$ & $-0.3 \% *$ \\
\hline \multicolumn{4}{|l|}{ Treatment } \\
\hline Monitor Meds: annual monitoring for members on $\mathrm{ACE} / \mathrm{ARB}(3,488,006 \mathrm{~W} ; 2,563,130 \mathrm{M})$ & $91.5 \%$ & $90.9 \%$ & $0.7 \% \div$ \\
\hline Monitor Meds: ...Digoxin $(210,912 \mathrm{~W} ; 182,693 \mathrm{M})$ & $93.3 \%$ & $93.0 \%$ & $0.2 \% \dagger$ \\
\hline Monitor Meds: ....Diuretics (3,098,194 W; 1,747,243 M) & $91.4 \%$ & $91.4 \%$ & $0.1 \% \dagger$ \\
\hline Monitor Meds: ...Anticonvulsants ${ }^{2}(120,141 \mathrm{~W} ; 105,863 \mathrm{M})$ & $69.8 \%$ & $70.6 \%$ & $-0.8 \%+$ \\
\hline Monitor Meds: Sum (4,815,562 W; 3,249,006 M) & $90.8 \%$ & $90.3 \%$ & $0.5 \%$ \\
\hline Persistent beta-blocker Tx $(36,030 \mathrm{~W} ; 42,224 \mathrm{M})$ & $84.7 \%$ & $82.5 \%$ & $2.2 \%+$ \\
\hline Rheumatoid arthritis Tx $(159,575 \mathrm{~W} ; 49,758 \mathrm{M})$ & $75.3 \%$ & $72.6 \%$ & $2.6 \%$ \\
\hline $\begin{array}{l}\text { Avoiding potentially harmful drug-disease interactions in elderly patients with chronic renal } \\
\text { failure }^{1,2}(67,767 \mathrm{~W} ; 67,510 \mathrm{M})\end{array}$ & $88.1 \%$ & $90.4 \%$ & $-2.3 \%$ \\
\hline $\begin{array}{l}\text { Avoiding potentially harmful drug-disease interactions in elderly patients with dementia, } \\
(620,186 \mathrm{~W} ; 320,438 \mathrm{M})\end{array}$ & $71.4 \%$ & $77.7 \%$ & $-6.4 \%+\S$ \\
\hline $\begin{array}{l}\text { Avoiding potentially harmful drug-disease interactions in elderly patients with a history of falls } \\
(517,539 \mathrm{~W} ; 205,052 \mathrm{M})\end{array}$ & $83.0 \%$ & $86.7 \%$ & $-3.7 \%$ \\
\hline Follow-up after hospitalization for mental illness: 30 days $(41,693 \mathrm{~W} ; 30,188 \mathrm{M})$ & $59.0 \%$ & $51.5 \%$ & $7.5 \% \doteqdot \S$ \\
\hline Follow-up after hospitalization for mental illness: 7 days $(41,693 \mathrm{~W} ; 30,188 \mathrm{M})$ & $40.0 \%$ & $34.9 \%$ & $5.0 \%+8$ \\
\hline Initiation of Alc/Drug Tx, $18+(128,685 \mathrm{~W} ; 165,548 \mathrm{M})$ & $52.0 \%$ & $50.6 \%$ & $1.4 \%+$ \\
\hline Pharmacotherapy Mgmt of COPD exacerbation: systemic corticosteroid $(72,890 \mathrm{~W} ; 58,028 \mathrm{M})$ & $65.1 \%$ & $63.7 \%$ & $1.4 \%+$ \\
\hline Pharmacotherapy Mgmt of COPD exacerbation: bronchodilator $(72,890 \mathrm{~W} ; 58,028 \mathrm{M})$ & $77.2 \%$ & $74.0 \%$ & $3.2 \%+$ \\
\hline Antidepressant med mgmt, acute phase (stay on meds 12 weeks) $(112,740 \mathrm{~W} ; 51,751 \mathrm{M})$ & $69.5 \%$ & $69.4 \%$ & $0.1 \%$ \\
\hline Antidepressant med mgmt, continuation phase (stay on meds 6 months) $(112,740 \mathrm{~W} ; 51,751 \mathrm{M})$ & $56.4 \%$ & $55.3 \%$ & $1.1 \% \ddagger$ \\
\hline \multicolumn{4}{|l|}{ Intermediate outcome } \\
\hline Cardio $L D L-C<100 \mathrm{mg} / \mathrm{dL}^{2}(159,098 \mathrm{~W} ; 277,173 \mathrm{M})$ & $42.9 \%$ & $49.7 \%$ & $-6.7 \%+\S$ \\
\hline Controlling high blood pressure (adequately controlled $<140 / 90)^{2}(196,867 \mathrm{~W} ; 144,416 \mathrm{M})$ & $57.0 \%$ & $59.3 \%$ & $-2.3 \%+$ \\
\hline Diabetes: HbA1c control < $8 \%(328,024 \mathrm{~W} ; 311,128 \mathrm{M})$ & $42.3 \%$ & $40.6 \%$ & $1.8 \%+$ \\
\hline Diabetes: $L D L-C$ control $<100 \mathrm{mg} / \mathrm{dL}^{2}(363,256 \mathrm{~W} ; 351,691 \mathrm{M})$ & $38.6 \%$ & $42.4 \%$ & $-3.9 \%$ \\
\hline Diabetes: blood pressure control < 140/00 mmHg $(306,405 \mathrm{~W} ; 294,061 \mathrm{M})$ & $25.0 \%$ & $24.2 \%$ & $0.8 \% \div$ \\
\hline \multicolumn{4}{|l|}{ Access } \\
\hline Access to preventive/ambulatory health services $(65+)(9,574,576 \mathrm{~W} ; 7,027,791 \mathrm{M})$ & $96.1 \%$ & $94.1 \%$ & $2.0 \% \ddagger$ \\
\hline
\end{tabular}

${ }^{*} p<0.05, t p<0.01, \ddagger p<0.001$ per $\chi^{2}$ test for dichotomous outcomes and per $t$ test for binomial outcomes

SDifferences between women and men exceed 5 percentage points

${ }^{7}$ The three measures that concern drug-disease interactions are here scored so that higher values indicate better care

${ }^{2}$ Measures in italics are those which favor men

management, acute phase $(p=0.56)$. Performance scores were higher for women than men for 22/32 measures; differences ranged from 7.5 percentage points higher for women on 30 day follow-up after hospitalization for myocardial infarction to 0.1 percentage point higher for monitoring medications: diuretics. The measures favoring women included $3 / 3$ primary screening measures, $4 / 6$ secondary screening measures, 12/17 treatment measures, $2 / 5$ intermediate outcome measures, and the 1 access measure. Of the 9 measures favoring men, 4 relate to cardiovascular disease and 3 to potentially harmful drugdisease interactions. Although 10 gender differences were small ( $<1$ percentage point), 6 exceeded 5 percentage point, including 1 measure favoring men.

The first column of Table 2 shows the odds of women receiving the indicated care compared to men, controlling for plan. When calculated within plans, 2 ORs were no longer statistically significant (1 favoring men) and the OR for 1 measure reversed from favoring women to favoring men.
As seen in the second column of Table 2, the informativeness of single-gender scores relative to overall scores was low. For 11/32 measures, informativeness was zero, indicating no evidence of variation in gender gap by plan (including $5 / 5$ intermediate outcome measures). These consistent gender gaps occurred for $7 / 9$ measures for which performance for men exceeds that for women.

Informativeness greater than zero implies that differences between women's and men's scores-hereafter the gender gap — vary by plan. Statistically significant plan-level correlations for 21 measures (7/9 screening measures, 13/17 treatment measures, and the single access measure, $p<0.001$ ) indicate plan-level variation in the gender gap. Of these measures, 15 have informativeness above 0.30 , with the highest (0.47) for pharmacotherapy management of chronic obstructive pulmonary disorder exacerbation: bronchodilator. For these 15 measures, the best plans for men and women may differ meaningfully. 
Table 2 Odds Ratios and Correlations of Plan HEDIS Performance by Gender

\begin{tabular}{|c|c|c|c|}
\hline$\overline{\text { Outcome }}$ & $\begin{array}{l}\text { Odds ratio for women } \\
\text { vs. men ( } 95 \% \text { confidence } \\
\text { interval) }\end{array}$ & $\begin{array}{l}\text { Informativeness } \\
\text { of performance } \\
\text { scores } \S\end{array}$ & $\begin{array}{l}\text { Correlation of gender } \\
\text { (female-male) } \\
\text { gap with overall } \\
\text { plan performance }\end{array}$ \\
\hline \multicolumn{4}{|l|}{ Primary screening } \\
\hline Adult BMI Assessment & $1.11(1.10-1.12) \dagger$ & 0.00 & $\mathrm{n} / \mathrm{a}$ \\
\hline Colorectal cancer screening & $1.07(1.05-1.09)$ & 0.26 & -0.25 \\
\hline Glaucoma Screening in Older Adults & $1.32(1.30-1.33) \div$ & 0.33 & $-0.11 \%$ \\
\hline \multicolumn{4}{|l|}{ Secondary screening } \\
\hline Cardio LDL-C screening ${ }^{2}$ & $0.95(0.93-0.97) \ddagger$ & 0.00 & $\mathrm{n} / \mathrm{a}$ \\
\hline Diabetes LDL-C screening & $1.09(1.07-1.12)$ & 0.31 & $-0.19 t$ \\
\hline Diabetes HbAlc testing & $1.19(1.16-1.22)+$ & 0.38 & $-0.23 t$ \\
\hline Diabetes eye exam & $1.28(1.26-1.30)$ & 0.29 & -0.06 \\
\hline Diabetes medical attention for nephropathy (microalbumin test or & $1.04(1.01-1.06) \dagger$ & 0.42 & 0.00 \\
\hline ACEI/ARB use) & & & \\
\hline Spirometry in $\mathrm{dx}$ of COPD & $1.00(0.98-1.02)$ & 0.28 & $-0.16^{*}$ \\
\hline \multicolumn{4}{|l|}{ Treatment } \\
\hline Monitor Meds: annual monitoring for members on ACE/ARB & $1.11(1.10-1.13) \ddagger$ & 0.31 & -0.02 \\
\hline Monitor Meds: ...Digoxin & $1.04(1.02-1.07)$ & 0.00 & $\mathrm{n} / \mathrm{a}$ \\
\hline Monitor Meds: ...Diuretics & $1.04(1.02-1.05) t$ & 0.29 & 0.00 \\
\hline Monitor Meds: ...Anticonvulsants ${ }^{2}$ & $0.96(0.93-0.98) \div$ & 0.36 & $0.17 *$ \\
\hline Monitor Meds: sum & $1.10(1.09-1.12) \ddagger$ & 0.33 & -0.02 \\
\hline Persistent beta-blocker Tx & $1.18(1.13-1.23)$ & 0.00 & $\mathrm{n} / \mathrm{a}$ \\
\hline Rheumatoid arthritis tx & $1.18(1.13-1.22)$ & 0.41 & $-0.41 t$ \\
\hline Avoiding potentially harmful drug-disease interactions in elderly & $0.80(0.78-0.83)+$ & 0.00 & $\mathrm{n} / \mathrm{a}$ \\
\hline \multicolumn{4}{|l|}{ patients with chronic renal failure, } \\
\hline $\begin{array}{l}\text { Avoiding potentially harmful drug-disease interactions in elderly } \\
\text { patients with dementia, }\end{array}$ & $0.70(0.68-0.71) \ddagger$ & 0.45 & 0.07 \\
\hline Avoiding potentially harmful drug-disease interactions in elderly & $0.75(0.74-0.76) \ddagger$ & 0.00 & $\mathrm{n} / \mathrm{a}$ \\
\hline Follow-up after hospitalization for mental illness: 30 days & $1.38(1.33-1.43) \ddagger$ & \multicolumn{2}{|c|}{ patients with a history of falls ${ }^{1,2}$} \\
\hline Follow-up after hospitalization for mental illness: 7 days & $1.26(1.21-1.31)$ & 0.28 & -0.11 \\
\hline Initiation of Alc/drug Tx, $18+$ & $0.99(0.96-1.03)$ & 0.41 & $0.17 t$ \\
\hline Pharmacotherapy Mgmt of COPD exacerbation: systemic & $1.05(1.02-1.08) \ddagger$ & 0.42 & $-0.14^{+}$ \\
\hline \multicolumn{4}{|l|}{ corticosteroid } \\
\hline Pharmacotherapy Mgmt of COPD exacerbation: bronchodilator & $1.17(1.13-1.21) \dagger$ & 0.47 & $-0.21 \dagger$ \\
\hline Antidepressant med mgmt, acute phase (stay on meds 12 weeks) & $1.01(0.98-1.04)$ & 0.34 & -0.10 \\
\hline Antidepressant med mgmt, continuation phase (stay on meds & $1.06(1.03-1.09) \dagger$ & 0.41 & 0.00 \\
\hline \multicolumn{4}{|l|}{6 months) } \\
\hline \multicolumn{4}{|l|}{ Intermediate outcome } \\
\hline Cardio $L D L-C<100 \mathrm{mg} / \mathrm{dL}^{2}$ & $0.71(0.70-0.73) \dagger$ & 0.00 & $\mathrm{n} / \mathrm{a}$ \\
\hline Controlling high blood pressure (adequately controlled $<140 / 90)^{2}$ & $0.89(0.88-0.91) \div$ & 0.00 & $\mathrm{n} / \mathrm{a}$ \\
\hline Diabetes: HbAlc control $<8 \%$ & $1.11(1.10-1.12)$ & 0.00 & $\mathrm{n} / \mathrm{a}$ \\
\hline Diabetes: $L D L-C$ control $<100 \mathrm{mg} / \mathrm{dL}^{2}$ & $0.80(0.79-0.81)$ & 0.00 & $\mathrm{n} / \mathrm{a}$ \\
\hline Diabetes: blood pressure control $<140 / 90 \mathrm{~mm} \mathrm{Hg}^{2}$ & $0.97(0.96-0.99) \dagger$ & 0.00 & $\mathrm{n} / \mathrm{a}$ \\
\hline \multicolumn{4}{|l|}{ Access } \\
\hline Access to preventive/ambulatory health services $(65+)$ & $1.60(1.56-1.65) \ddagger$ & 0.45 & $-0.38 \ddagger$ \\
\hline
\end{tabular}

$* p<0.05, t p<0.01, \neq p<0.001$

Results are from a series of binary mixed-effect regression models predicting HEDIS outcomes from a female fixed effect, random plan intercepts, and random plan slopes for female-male differences

SInformativeness is the proportion of variance for single gender plan scores not explained by the overall plan score. It is calculated as 1-R $R^{2}$ where $R$ is the disattenuated correlation of plan scores by gender, calculated as the plan intercept variance component divided by the sum of the plan intercept variance component and the plan-level random slope by gender variance component. These variance components are derived from the mixed effects regression models described above. Here, all non-zero values are statistically significantly different from zero $(p<.001)$

${ }^{I}$ We scored the three drug-disease interaction measures so that higher values reflect better care

${ }^{2}$ Measures in italics are those which favor men

Specifically, relative to women in low-performing plans, men in low-performing plans had even lower scores for these 15 measures than would otherwise be expected. As seen in the third column of Table 2, the correlation between gender differences (women vs. men) and overall plan performance was negative and statistically significant for 8 measures. On these 8 measures, women had higher performance scores than men. The correlation between gender differences and overall plan performance was positive and significant for 2 measures, 1 of which favored men and the other of which had no average gender gap within plans. Thus, for these 2 measures, the gap is more favorable to men in plans with higher scores.
The different ways gender gaps and overall scores are related can be illustrated with three examples from Table 2 . Within plans, women were more likely to receive the adult BMI assessment (significant OR of 1.11) and the informativeness of 0 is consistent with a constant true gender gap across plans. Diabetic women were also more likely than diabetic men to receive an eye exam (significant OR of 1.28), but the statistically significant informativeness $(0.29)$ indicates that the gender gap varies across plans. However, we did not find evidence that this gender gap was correlated with overall plan performance; it was not likely to be larger (or smaller) in lowperforming plans. Finally, women were more likely to receive 
a colorectal cancer screening $(\mathrm{OR}=1.07)$ and, as with eye exams, there was evidence that the gender gap varies across plans (informativeness $=0.26$ ). However, for this measure, the gender gap was also significantly negatively correlated with overall plan performance $(r=-.25)$, indicating that the gender gap tends to be less favorable to women in high-performing plans (and to men in low-performing plans).

Figure 1 illustrates how the gender gap varies across quintiles of plan performance for 4 measures with significant negative correlations between plan performance and the difference between performance scores of women and men. In the case of Rx therapy for rheumatoid arthritis and HbA1c testing for diabetics, the gender gap (favoring women) closes at high levels of overall plan performance where men's care is equivalent to women's. In the case of colorectal cancer screening, the gender gap closes and men's care exceeds women's care at high levels. Similarly, for adult access to preventive/ ambulatory services, performance scores are high in general, but gaps favoring women are large and narrow as overall performance increases. Thus, for all 4 of these measures, while quality of care increases for both genders across quintiles of care quality, the relative gains are greater for men than women, which results in a smaller gender disparity in the highestperforming quintile.

\section{DISCUSSION}

Our study demonstrates that among MA beneficiaries, women generally experienced better care than men (on 22/32 measures, almost all of which are screening or treatment measures). The only measures for which men's care was more than 1 percentage point higher than women's were intermediate outcome measures related to control of LDL-C and of high blood pressure, as well as treatment measures regarding potentially harmful drug-disease interactions. Although the plan-level correspondence between plan scores for women and men was generally high, the best-performing plan for women was not high-performing for men in some cases.

In the two areas with gaps favoring men, intermediate outcome measures related to control of cardiovascular risk factors and treatment measures regarding potentially harmful drugdisease interactions, point to aspects of health care which might place women at increased risk of poorer quality of care. Mosca and colleagues found that providers were more likely to assign women with intermediate cardiovascular risk as assessed by the Framingham Risk Score to a lower risk category than men with identical risk factors. ${ }^{22}$ They also found that providers were also less likely to prescribe statins to women and to increase the dose to achieve adequate LDL control, though this only partly explained the observed gender gaps in care. Similarly, in an analysis of preventive cardiovascular care among commercial managed care members in four metropolitan areas, Bird and colleagues found that LDL cholesterol control rates were 5 and 15 percentage points lower for women than men with diabetes mellitus $(p<.0001)$ and coronary artery disease $(p<.0001)$, respectively. ${ }^{23}$ They found that younger women were underidentified by a widely used algorithm to identify individuals for referral to disease management and wellness behavior support programs. In the case of potentially harmful drugdisease interactions, women's poorer quality of care may be a function of their higher rates of comorbidities and associated risks of polypharmacy. Although women's health may expose them to greater risk of drug-disease interactions, this would not be a justification for not receiving guideline concordant care.

We also found that the gender gap is often larger in plans that perform poorly overall. On some measures for which women score higher than men, the difference tends to be smaller for high-performing plans. On measures for which men score higher than women, the gender gap typically varies little across plans. The findings suggest that stratifying quality assessments by gender could identify plans where either women or men are receiving worse care than expected based on what is known about plan performance. Gender-based quality reporting may also motivate quality improvement efforts for the lagging group. ${ }^{14}$ This approach could be used in setting priorities and to monitor whether improvement efforts benefit both women and men. The information may also raise clinicians' awareness of potential gender gaps in care of seniors. Provider groups and plans may need to coordinate to improve services. Moreover, our findings confirm the additional challenges of achieving equity for women on control measures compared to process measures, also a challenge for racial/ethnic disparities. ${ }^{5,24}$

Even small unexplained disparities in performance by gender signal faults in the delivery system that should be addressed. By analogy, very few planes crash and cause passenger deaths, but when they do, they present an opportunity to examine factors that contribute and create remedies that reduce future crashes and prevent other problems. Although gender differences in quality-of-care measures were often less than five percentage points, they reflect the care of millions of seniors. Therefore, a substantial number of people might benefit if gender gaps were closed through improvement for lagging groups. For example, $70.2 \%$ of women and $64.7 \%$ of men received glaucoma screening. In 2011, men accounted for $44 \%$ of approximately 56 million beneficiaries. Matching the female rate would add $\sim 1.4$ million glaucoma screenings. Likewise, given the importance of cardiovascular care for reducing mortality, many deaths might be prevented by increasing women's quality of cardiovascular care to the average level currently received by men.

Gender differences, which are nearly constant across plans for some measures, suggest an opportunity to make gender gaps visible to plans, providers, and older adults and their families so that they will take actions to improve care and reduce gender disparities in quality. HEDIS data reporting has been used in the MA program since 2002 to measure disparities in care. ${ }^{25}$ MA plans have several tools at their disposal to improve quality including education, reminders, and prompts 
Drug therapy for rheumatoid arthritis

Female log-odds: $0.16(p=<.001)$. Slope-intercept corr: $-0.41(p=<.001)$

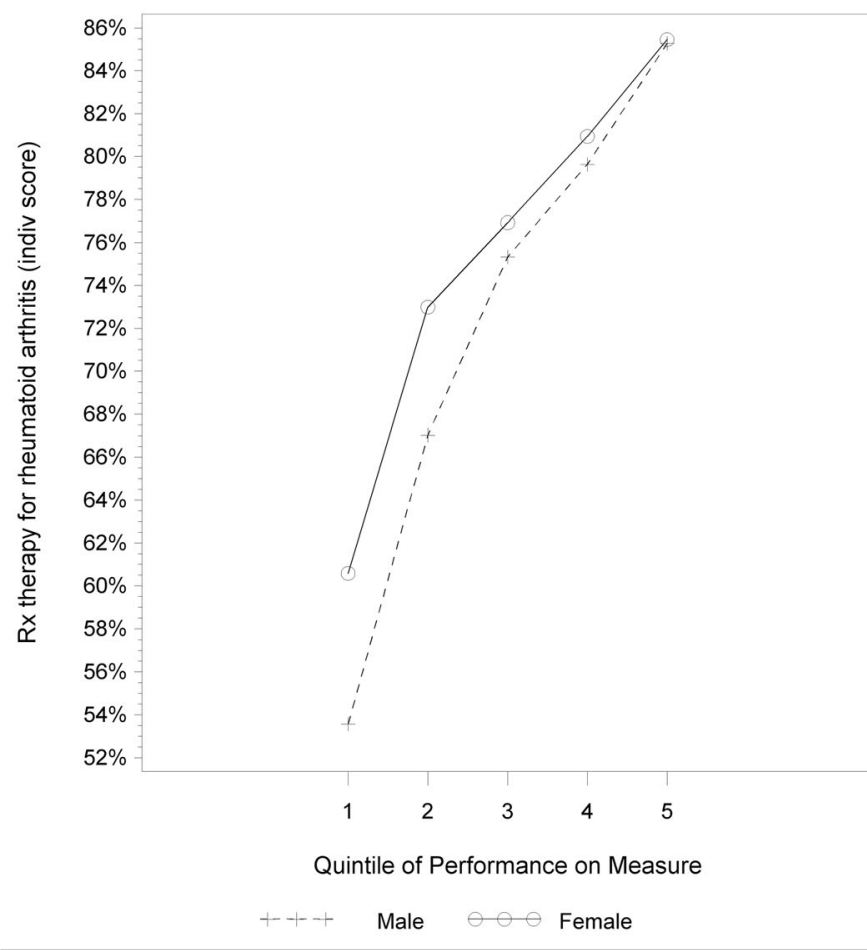

Access to preventive and ambulatory health services Female log-odds: $0.47(p=<.001)$. Slope-intercept corr: $-0.38(p=<.001)$

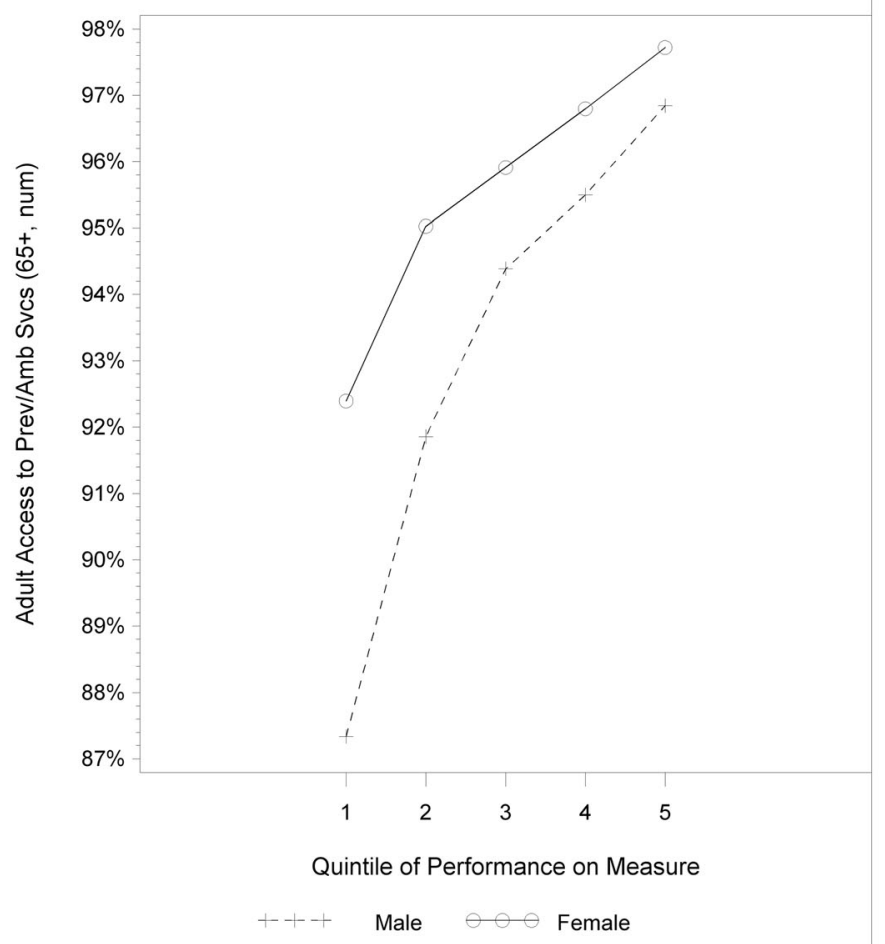

Colorectal cancer screening

Female log-odds: $0.07(p=<.001)$. Slope-intercept corr: $-0.25(p=<.001)$

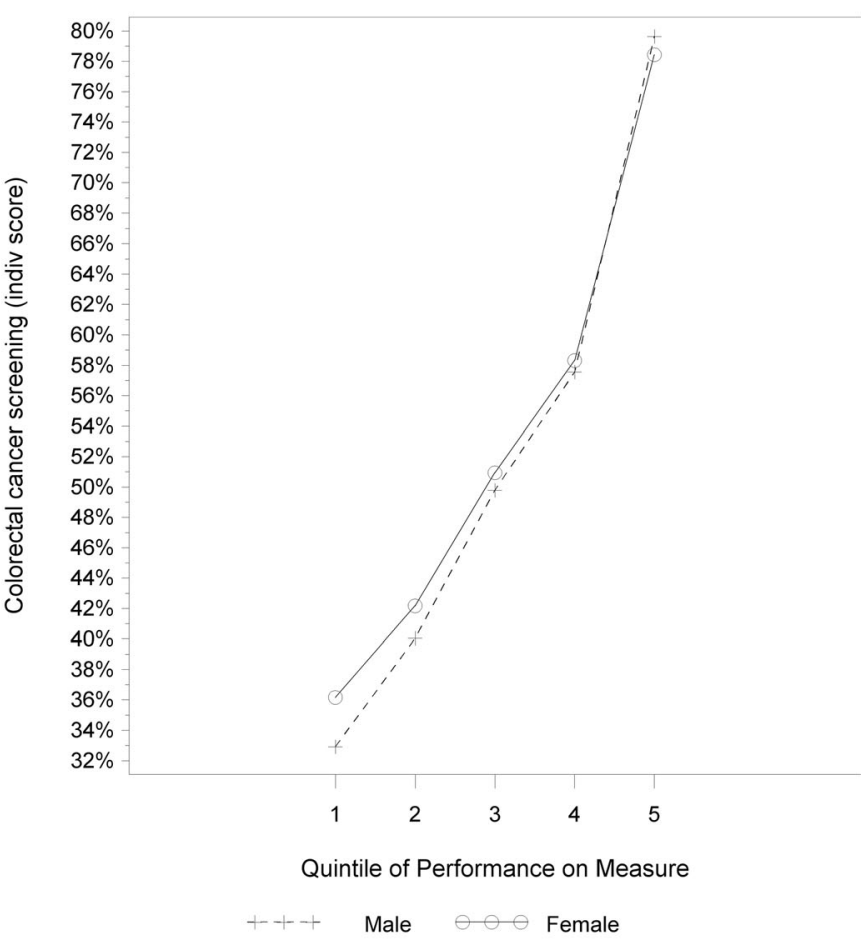

$\mathrm{HbA} 1 \mathrm{c}$ testing for diabetics

Female log-odds: $0.17(p=<.001)$. Slope-intercept corr: $-0.23(p=<.001)$

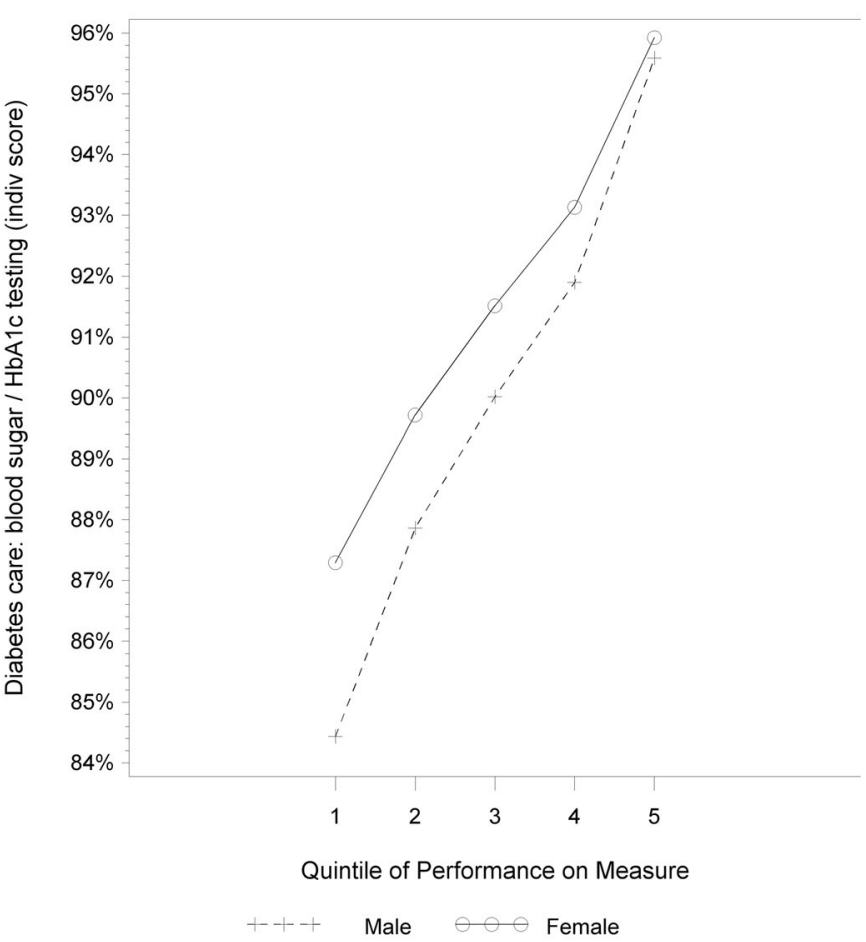

Figure 1 Women's and men's HEDIS performance scores by Plan performance quintile. Notes: $p \leq 0.001$. Male $=$ dashed line Female $=$ solid line

for both beneficiaries and providers. They can also use payment incentives and contracting requirements to motivate improvement. Addressing gender gaps among MA beneficiaries might also drive efforts to address gaps in employer-sponsored care which in turn could lead to improved health trajectories of older women and men as well as Medicare cost savings. 
This study has several limitations. We can only speculate about the underlying causes of these gender differences. They may reflect differential treatment by the same providers, differences in the quality of providers seen within plans, differences in patients' health behaviors (including preferences and adherence to provider recommendations), or, for control measures, gender differences in tolerance of medications and response to treatment. ${ }^{26}$ However, for some plans and measures, particularly for high-performing plans and screening or treatment measures, no gender gap exists. Although we lacked information on patient health and comorbidities, these quality measures refer specifically to care for which there is clinical consensus that it is indicated for the entire population for which it is assessed; the denominator specification for each measure includes only beneficiaries who meet the eligibility criteria for the service specified by the measure numerator.

These limitations notwithstanding, these results have important clinical implications. HEDIS measures offer evidencebased standards of care for which there is general agreement. The observed gender disparities could result in adverse outcomes for men across the wide range of measures for which they experienced worse care and adverse outcomes for women in the areas of cardiovascular care and potentially harmful drug-disease interactions. Further reduction in women's morbidity and mortality from cardiovascular disease depends on better addressing the disease and its risk factors in ambulatory practice and in reducing drug-disease interactions. Further research is needed to assess the underlying causes of genderspecific gaps in system performance and associated opportunities to improve care and outcomes.

Corresponding Author: Marc N. Elliott, PhD; RAND Corporation, Santa Monica, CA, USA (e-mail: Elliott@rand.org).

Contributors We would like to thank Fergal McCarthy, M.Phil. and Biayna Darabidian, B.A. for assistance with manuscript preparation.

Funding This work was supported by funding from the Centers for Medicare and Medicaid Services (CMS), contract GS-10F-0275P.

\section{Compliance with ethical standards:}

\section{Prior presentations: ARM 2015, Minneapolis, MN.}

Conflict of interest: Chloe E. Bird does not have a conflict of interest. Marc N. Elliott does not have a conflict of interest. John L. Adams does not have a conflict of interest. Eric C. Schneider does not have a conflict of interest. David J. Klein does not have a conflict of interest. Jacob W. Dembosky does not have a conflict of interest. Sarah Gaillot does not have a conflict of interest, although please note Sarah is an employee of the sponsoring agency, Centers for Medicare and Medicaid Services. Allen M. Fremont does not have a conflict of interest. Amelia M. Haviland does not have a conflict of interest.

\section{REFERENCES}

1. The National Academies of Sciences E, \& Medicine. Systems Practices for the Care of Socially At-Risk Populations. Washington, DC: The National Academies of Sciences, Engineering, \& Medicine 2016.
2. The National Academies of Sciences E, \& Medicine. Accounting for Social Risk Factors in Medicare Payment: Identifying Social Risk Factors. Washington, DC: The National Academies of Sciences, Engineering, \& Medicine 2016

3. The National Academies of Sciences E, \& Medicine. Accounting for Social Risk Factors in Medicare Payment: Data. Washington, DC: The National Academies of Sciences, Engineering, \& Medicine 2016.

4. The National Academies of Sciences E, \& Medicine. Accounting for social risk factors in Medicare payment: Criteria, factors and methods. Washington, DC: The National Academies of Sciences, Engineering, \& Medicine 2016.

5. Trivedi AN, Zaslavsky AM, Schneider EC, Ayanian JZ. Trends in the quality of care and racial disparities in Medicare managed care. N Engl J Med. 2005;353(7):692-700. doi:https://doi.org/10.1056/ NEJMsa051207

6. Anderson RE, Ayanian JZ, Zaslavsky AM, McWilliams JM. Quality of care and racial disparities in medicare among potential ACOs. J Gen Intern Med. 2014;29(9): 1296-304. doi:https://doi.org/10.1007/s11606014-2900-3

7. Asch SM, Kerr EA, Keesey J, Adams JL, Setodji CM, Malik S, et al. Who is at greatest risk for receiving poor-quality health care? N Engl J Med. 2006;354(11):1147-56. doi:https://doi.org/10.1056/ NEJMsa044464

8. Verbrugge LM, Steiner RP. Physician treatment of men and women patients: sex bias or appropriate care? Med Care. 1981;19(6):609-32.

9. Bird CE, Fremont AM, Bierman AS, Wickstrom S, Shah M, Rector T, et al. Does quality of care for cardiovascular disease and diabetes differ by gender for enrollees in managed care plans? Womens Health Issues. 2007;17(3):131-8. doi:https://doi.org/10.1016/j.whi.2007.03.001

10. Chou AF, Brown AF, Jensen RE, Shih SC, Pawlson G, Scholle SH. Gender and racial disparities in the management of diabetes mellitus among Medicare patients. Womens Health Issues. 2007;17(3):150-61. doi:https://doi.org/10.1016/j.whi.2007.03.003

11. Chou AF, Wong L, Weisman CS, Chan S, Bierman AS, Correa-deAraujo R, et al. Gender disparities in cardiovascular disease care among commercial and medicare managed care plans. Womens Health Issues. 2007;17(3):139-49. doi:https://doi.org/10.1016/j.whi.2007.03.004

12. Chou AF, Scholle SH, Weisman CS, Bierman AS, Correa-de-Araujo R, Mosca L. Gender disparities in the quality of cardiovascular disease care in private managed care plans. Womens Health Issues. 2007;17(3):12030. doi:https://doi.org/10.1016/j.whi.2007.03.002

13. Eisenman D, Bogart LM, Bird CE, Collins RL, Golinelli D, Fremont A, et al. Differential diffusion of HIV technologies by gender: the case of highly active antiretroviral therapy. AIDS patient care and STDs. 2007;21(6):390-9. doi:https://doi.org/10.1089/apc.2006.0061

14. Fremont A.M., Correa-de-Araujo R., Hayes SN. Gender disparities in managed care: it's time for action. Womens Health Issues. 2007; 17(3): 116-9.

15. Aziz M, Smith KY. Challenges and successes in linking HIV-infected women to care in the United States. Clin Infect Dis. 2011;52 Suppl 2:S231-7. doi:https://doi.org/10.1093/cid/ciq047

16. Martino SC, Weinick RM, Kanouse DE, Brown JA, Haviland AM, Goldstein E, et al. Reporting CAHPS and HEDIS data by race/ethnicity for Medicare beneficiaries. Health Serv Res. 2013;48(2 Pt 1):417-34. doi:https://doi.org/10.1111/j.1475-6773.2012.01452.x

17. National Committee for Quality Assurance. What Is HEDIS? 2011. http://www.ncqa.org/HEDISQualityMeasurement/WhatisHEDIS.aspx. Accessed April 232013.

18. National Committee for Quality Assurance. HEDIS \& Quality Measurement 2013. National Committee for Quality Assurance,, Washington, DC. 2013. http://www.ncqa.org/hedis-quality-measurement/hedis-measures/hedis-archives. Accessed June 232016.

19. Schneider EC, Nadel MR, Zaslavsky AM, McGlynn EA. Assessment of the scientific soundness of clinical performance measures: a field test of the National Committee for Quality Assurance's colorectal cancer screening measure. Arch Intern Med. 2008;168(8):876-82. doi:https:// doi.org/10.1001/archinte.168.8.876

20. National Committee for Quality Assurance. HEDIS Compliance Audit Program. National Committee for Quality Assurance. http://www.ncqa. org/tabid/205/Default.aspx

21. Raudenbush Sw, Bryk AS. Hierarchical linear models: Applications and data analysis methods. 2nd ed. Newbury Park, CA: SAGE Publications; 2002.

22. Mosca L, Linfante AH, Benjamin EJ, Berra K, Hayes SN, Walsh BW, et al. National Study of Physician Awareness and Adherence to Cardiovascular Disease Prevention Guidelines. Circulation. 2005;111(4):499510. 
23. Bird CE, Manocchia M, Tomblin B, Payne P, Kulakodlu M, Iacolo Emily, et al. Mapping the gaps: Gender differences in preventive cardiovascular care among managed care members in four metropolitan areas. Womens Health Issues. 2018. https://doi.org/10.1016/j.whi.2018.04.008

24. Ayanian JZ, Landon BE, Newhouse JP, Zaslavsky AM. Racial and ethnic disparities among enrollees in Medicare Advantage plans. N Engl J Med. 2014;371(24):2288-97. https://doi.org/10.1056/ NEJMsa 1407273
25. Schneider EC, Zaslavsky AM, Epstein AM. Racial disparities in the quality of care for enrollees in medicare managed care. JAMA. 2002;287(10):1288-94.

26. Billimek J, Malik S, Sorkin DH, Schmalbach P, Ngo-Metzger $\mathbf{Q}$, Greenfield $\mathbf{S}$, et al. Understanding disparities in lipid management among patients with type 2 diabetes: gender differences in medication nonadherence after treatment intensification. Womens Health Issues. 2015;25(1):6-12. doi:https://doi.org/10.1016/j.whi.2014.09.004 